\title{
AVALIAÇÃO DO DESEMPENHO E DE PARÂMETROS GASTRINTESTINAIS DE FRANGOS DE CORTE ALIMENTADOS COM DIETAS FORMULADAS COM SORGO ALTO TANINO E BAIXO TANINO
}

\author{
Evaluation of performance and gastric parameters of broiler chickens fed diets \\ formulateds with sorghum with and no tannin
}

\author{
Rodrigo Garófallo Garcia ${ }^{1}$, Ariel Antonio Mendes ${ }^{2}$, Carla de Andrade ${ }^{3}$, Ibiara Correia de Lima Almeida Paz, \\ Sabrina Endo Takahashi ${ }^{1}$, Kléber Pelícia ${ }^{1}$, Claudia Marie Komiyama ${ }^{1}$, Renata Rangel Quinteiro ${ }^{1}$
}

\begin{abstract}
RESUMO
O experimento foi realizado nas instalações experimentais da Faculdade de Medicina Veterinária e Zootecnia da Unesp, Campus de Botucatu e objetivou-se avaliar o efeito das dietas com milho e farelo de soja, sorgo com alto tanino e farelo de soja e sorgo com baixo tanino e farelo de soja sobre o desempenho, rendimento de carcaça e parâmetros gastrintestinais de frangos de corte. Foram utilizados 1200 pintos de corte de um dia, da linhagem Ross 308, distribuídos em 24 boxes em um delineamento experimental inteiramente casualizado em esquema fatorial $3 \times 2$, três dietas: $100 \%$ milho e farelo de soja, $100 \%$ sorgo com alto tanino e farelo de soja (SAT) e 100\% sorgo com baixo tanino e farelo de soja (SBT) e dois sexos, com 4 repetições de 50 aves cada. O desempenho foi avaliado aos 21, 35 e 42 dias de idade e aos 42 dias de idade, uma amostra de 5 aves por repetição foi abatida para a determinação do rendimento de carcaça e das partes. Foram medidos o rendimento do peito desossado, coxa e sobrecoxa, asas, dorso e gordura abdominal. Aos 14, 21, 28, 35 e 42 dias de idade foram sacrificadas 3 aves por repetição para avaliação do desenvolvimento das vísceras e dos intestinos por meio de pesagens e medidas. Conclui-se que, ao utilizar sorgo com alto tanino (cultivar AG3002 com 1,89 $\mathrm{g} / \mathrm{kg}$ ) e sorgo com baixo tanino (cultivar SAARA com 0,49 g/ $\mathrm{kg}$ ) em substituição ao milho não foi encontrado efeito significativo ( $>0,05)$ para os parâmetros analisados de desempenho e rendimento de carcaça, não ocorrendo também efeito evidente sobre a porcentagem das vísceras e intestinos e as medidas dos intestinos.
\end{abstract}

Termos para indexação: Desempenho, frangos de corte, intestinos, sorgo, tanino.

ABSTRACT

The experiment was carried out in the experimental facilities of Faculdade de Medicina Veterinária e Zootecnia of Unesp, Botucatu Campus and the objective was evaluate the effect of corn, sorghum with tannin and sorghum no tannin-based diets on the gastric and bowel parameters in broiler. One thousand and two hundred sexed Ross 308, one-day-old chicks were used, divided in 24 boxes in an completely randomized experimental design with factorial arrangement 3x2, three diets: $100 \%$ corn, $100 \%$ sorghum with tannin (SAT) and $100 \%$ sorghum without tannin (SBT) and two sexes, with 4 replications of 50 birds each The broiler performance was evaluate at 21, 35 and 42 days of age. At 42 days of age, a sample of 5 birds per replication was slaughtered to carcass yield determination. At 14,21, 28, 35 and 42 days of age 3 birds per replication were slaughtered for the evaluation of guts and bowel development by means of weighing and measurements. It can be concluded that, when using sorghum with tannin (AG3002 crop with $1.89 \mathrm{~g} / \mathrm{kg}$ ) and sorghum no tannin (SAARA crop, with $0.49 \mathrm{~g} / \mathrm{kg}$ ) replacing corn, there was no evident effect (p>.05) on performance, carcass yield, as well as on guts and bowel percentage or on the bowel measures.

Index terms: broiler chickens, carcass yield, sorghum, performance, tannin.

(Recebido para publicação em 30 de abril de 2004 e aprovado em 10 de outubro de 2005)

\section{INTRODUÇÃO}

Embora a utilização do sorgo na alimentação de aves tenha sido muito pesquisada no Brasil nas décadas de setenta e oitenta, o assunto deve ser revisto devido ao surgimento de novas cultivares melhoradas geneticamente e linhagens novas de frangos de corte. Apesar da maior parte do sorgo produzido hoje no Brasil possuir baixo tanino, em algumas regiões como o Sul e o Nordeste, há a necessidade do cultivo de variedades com alto teor de tanino devido à susceptibilidade do grão ao ataque de pássaros. Pesquisas mais recentes sugerem que o sorgo com alto tanino pode resultar em problemas no trato digestivo e na própria digestibilidade dos nutrientes da dieta, o que pode levar a diminuição do desempenho das aves.

O sorgo é um importante cereal, estando em quinto lugar entre os grãos mais produzidos no mundo, atrás apenas do trigo, milho, arroz e da cevada. Uma de suas características é ser mais resistente à seca que o milho, sendo este um fator importante, pois a cultura pode ser

\footnotetext{
${ }^{1}$ Alunos(as) do Programa de Pós-Graduação em Zootecnia da Faculdade de Medicina Veterinária e Zootecnia/UNESP - Campus de Botucatu Fazenda Experimental Lageado s/n - 18.618-000 - garofallo@fca.unesp.br

²Docente da Faculdade de Medicina Veterinária e Zootecnia/UNESP - Campus de Botucatu.

${ }^{3}$ Alunos de Graduação em Zootecnia da Faculdade de Medicina Veterinária e Zootecnia/UNESP - Campus de Botucatu.
} 
implantada em regiões com baixa pluviosidade (GUALTIERI $\&$ RAPACCINI, 1990). Existe uma grande variedade de cultivares de sorgo, as quais podem apresentar grãos com características químicas e biológicas diferentes (LEESON \& SUMMERS, 1991).

O consumo de ração é afetado por inúmeros fatores relacionados ao estado físiológico do animal, meio ambiente, características da dieta ou uma interação entre todos estes fatores (SCOTT et al., 1982). Vários estudos relataram uma redução significativa no consumo de ração por frangos alimentados com dietas contendo sorgo (IBRAHIM et al., 1991) e este efeito tem sido atribuído ao sabor adstringente do tanino (TREVINO et al., 1992). Entretanto, como as aves não apresentam paladar desenvolvido (MORAN, 1982), parece improvável que o sabor seja a causa da diminuição no consumo de ração. Musharaf \& Latshaw (1991) não encontraram redução significativa no consumo de frangos de corte quando substituíram o milho da dieta por até $62 \%$ de sorgo de baixo teor de tanino. Já Trevino et al. (1992) relataram um aumento não-significativo no consumo de ração em frangos alimentados com sorgo com alto tanino.

$\mathrm{O}$ crescimento de frangos de corte, geralmente, apresenta redução com a presença de tanino na dieta, provavelmente porque o tanino reduz a utilização de energia, proteína e alguns aminoácidos (ELKIN et al., 1995). Douglas et al. (1990) afirmam que houve decréscimos lineares da energia digestível e energia metabolizável, à medida que o teor de tanino aumentou no grão de sorgo. Porém, outros estudos não relatam efeito sobre o ganho de peso quando o sorgo foi utilizado na ração (MUSHARAF \& LATSHAW, 1991).

Existem trabalhos que relatam piora na conversão alimentar ao se adicionar sorgo na ração (HASLAM, 1981). Douglas et al. (1990) forneceram ração contendo 53\% de sorgo com alto tanino para frangos de corte e observaram uma redução de $16 \%$ na eficiência alimentar, enquanto as aves que receberam ração com sorgo com baixo tanino apresentaram redução de apenas 1,15\%. Rostagno et al. (2000) observaram redução nos valores de energia metabolizável e na digestibilidade dos principais aminoácidos entre o sorgo com baixo tanino e alto tanino para aves.

O tanino reduz o valor nutricional da dieta, principalmente por diminuir a utilização das proteínas e reduzir a atividade das enzimas digestivas (HASLAM, 1981). Segundo Nunes et al. (2001), os taninos condensados são os responsáveis metabolicamente pela inibição de algumas enzimas presentes no sistema digestivo, diminuindo assim, a absorção dos nutrientes por meio da parede intestinal.

A utilização de sorgo na ração de frangos pode promover alterações na integridade da mucosa intestinal. Alguns autores observaram necroses na mucosa gastroduodenal e erosões na superfície das mucosas (MITJAVILA et al., 1977), reduzindo a capacidade de absorção do trato gastrintestinal, contribuindo assim, para a diminuição do desempenho das aves. Estudos realizados por Nunes et al. (2001) e Ortiz et al. (1994), com aves em crescimento, consumindo dietas contendo $0 ; 8$ e $16 \mathrm{~g} / \mathrm{kg}$ de tanino, apresentaram mudanças histológicas significativas na mucosa intestinal das aves. Os mesmos autores detectaram atrofia na mucosa do íleo e encurtamento das vilosidades, distorção de sua arquitetura, edema no tecido conectivo das vilosidades, hiperplasia e hipertrofia das células de goblet, além de hipertrofia da glândula parótida (MAGALHÃES et al., 1997).

O peso dos órgãos é geralmente avaliado na observação da resposta do organismo animal a certos tratamentos (BROWN et al., 1985), já que esses órgãos podem apresentar uma hipo ou hipertrofia dependendo das condições nutricionais as quais são submetidos (AHMED et al., 1991; NYVACHOT \& ATKINSON, 1995). Segundo Martins et al. (2000), os frangos de corte têm uma grande capacidade de absorção dos nutrientes pelo trato digestivo e alguns componentes da dieta, juntamente com o conteúdo da microbiota intestinal, podem modificar a mucosa no seu metabolismo, resultando em um espessamento da parede intestinal e diminuição da capacidade de digestão e absorção dos nutrientes.

Com base nestes aspectos, objetivou-se com este experimento foram avaliar o efeito de dietas com milho e farelo de soja, sorgo com alto tanino e farelo de soja e sorgo com baixo tanino e farelo de soja sobre o desempenho e rendimento de carcaça das aves, desenvolvimento do proventrículo, moela, pâncreas, fígado e intestinos aos 14, $21,28,35$ e 42 dias de idade.

\section{MATERIAL E MÉTODOS}

$\mathrm{O}$ experimento foi realizado nas instalações experimentais da Faculdade de Medicina Veterinária e Zootecnia da Unesp, Campus de Botucatu. Foram utilizados 1200 pintos de corte de um dia, da linhagem Ross 308, distribuídos em 24 boxes em um delineamento experimental inteiramente casualizado em esquema fatorial $3 \times 2$, três dietas, ou seja, $100 \%$ milho e farelo de soja, $100 \%$ sorgo com alto tanino e farelo de soja (SAT) e $100 \%$ sorgo com baixo tanino e farelo de soja (SBT) e dois sexos, com 4 repetições de 50 aves cada um. 
Os grãos de sorgo utilizados são das variedades AG3002 (alto tanino) produzidas na Fazenda de Ensino, Pesquisa e Produção da FMVZ - UNESP e SAARA (baixo tanino) fornecidos pela empresa MONSANTO® de Uberlândia, MG.

As aves receberam ração (Tabela 1) e água à vontade durante todo o período de criação, que foi dividido em três fases: inicial (1 a 21 dias), crescimento (22 a 35 dias) e final ( 35 a 42 dias).

Aos 14, 21, 28, 35 e 42 dias de idade foram sacrificadas 3 aves por repetição (72 aves no total/coleta) para avaliação do desenvolvimento do pró-ventrículo, moela, fígado, pâncreas e intestinos por meio de pesagens e medidas destes órgãos.

Aos 42 dias de idade, uma amostra de 5 aves por repetição foi abatida no Abatedouro Experimental da Faculdade de Medicina Veterinária e Zootecnia da UNESP, Campus de Botucatu. A determinação do rendimento de carcaça e das partes foi realizada de acordo com Mendes (1990). Foram medidos o rendimento do peito inteiro e desossado, perna inteira e desossada, asas, dorso e gordura abdominal. Os valores percentuais do rendimento de carcaça foram calculados em relação ao peso vivo, enquanto que o rendimento de cada parte foi calculado em relação ao peso da carcaça eviscerada.

TABELA 1 - Composição percentual e calculada das rações experimentais.

\begin{tabular}{|c|c|c|c|c|c|c|c|c|c|}
\hline \multirow{2}{*}{ Ingredientes } & \multicolumn{3}{|c|}{ Inicial } & \multicolumn{3}{|c|}{ Crescimento } & \multicolumn{3}{|c|}{ Final } \\
\hline & Milho & SAT & SBT & Milho & SAT & SBT & Milho & SAT & SBT \\
\hline Milho moído & 57,060 & - & - & 61,650 & - & - & 67,040 & - & - \\
\hline Farelo de soja & 36,286 & 34,698 & 34,748 & 30,986 & 32,343 & 30,882 & 26,810 & 25,614 & 25,065 \\
\hline Sorgo moído & - & 57,094 & 57,062 & - & 58,667 & 60,476 & - & 66,523 & 67,122 \\
\hline Óleo de soja & 2,977 & 4,400 & 4,400 & 4,000 & 5,536 & 5,236 & 4,285 & 5,848 & 5,848 \\
\hline DL-metionina & 0,231 & 0,235 & 0,231 & 0,150 & 0,273 & 0,168 & 0,162 & 0,147 & 0,148 \\
\hline Lisina & 0,150 & 0,264 & 0,263 & 0,192 & 0,196 & 0,249 & 0,187 & 0,269 & 0,268 \\
\hline Fosfato Bic. & 1,814 & 1,824 & 1,814 & 1,614 & 1,578 & 1,582 & 0,483 & 0,463 & 0,453 \\
\hline Calc. Calcítico & 0,982 & 0,985 & 0,982 & 0,928 & 0,927 & 0,927 & 0,638 & 0,676 & 0,636 \\
\hline S. Vitamínico* & 0,100 & 0,100 & 0,100 & 0,080 & 0,080 & 0,080 & 0,060 & 0,060 & 0,060 \\
\hline S. Mineral* & 0,050 & 0,50 & 0,050 & 0,050 & 0,050 & 0,050 & 0,050 & 0,050 & 0,050 \\
\hline Sal & 0,350 & 0,350 & 0,350 & 0,350 & 0,350 & 0,350 & 0,350 & 0,350 & 0,350 \\
\hline Total & 100,00 & 100,00 & 100,00 & 100,00 & 100,00 & 100,00 & 100,00 & 100,00 & 100,00 \\
\hline \multicolumn{10}{|l|}{ Calculada } \\
\hline EM (kcal/kg) & 3000 & 3000 & 3000 & 3100 & 3100 & 3100 & 3200 & 3200 & 3200 \\
\hline P. Bruta $(\%)$ & 21,396 & 21,396 & 21,396 & 19,313 & 19,313 & 19,313 & 18,048 & 18,048 & 18,048 \\
\hline Cálcio (\%) & 0,960 & 0,960 & 0,960 & 0,874 & 0,874 & 0,874 & 0,800 & 0,800 & 0,800 \\
\hline Fosf. disp. (\%) & 0,450 & 0,450 & 0,450 & 0,406 & 0,406 & 0,406 & 0,365 & 0,365 & 0,365 \\
\hline DL-met.(\%) & 0,492 & 0,492 & 0,492 & 0,453 & 0,453 & 0,453 & 0,410 & 0,410 & 0,410 \\
\hline Met + Cist. (\%) & 0,897 & 0,897 & 0,897 & 0,765 & 0,765 & 0,765 & 0,742 & 0,742 & 0,742 \\
\hline Lisina $(\%)$ & 1,263 & 1,263 & 1,263 & 1,156 & 1,156 & 1,156 & 1,040 & 1,040 & 1,040 \\
\hline Triptofano (\%) & 0,207 & 0,207 & 0,207 & 0,238 & 0,238 & 0,238 & 0,182 & 0,182 & 0,182 \\
\hline Treonina $(\%)$ & 0,795 & 0,795 & 0,795 & 0,752 & 0,752 & 0,752 & 0,634 & 0,634 & 0,634 \\
\hline $\mathrm{K}(\%)$ & 0,501 & 0,501 & 0,501 & 0,752 & 0,752 & 0,752 & 0,454 & 0,454 & 0,454 \\
\hline $\mathrm{Na}(\%)$ & 0,222 & 0,222 & 0,222 & 0,178 & 0,178 & 0,178 & 0,192 & 0,192 & 0,192 \\
\hline $\mathrm{Cl}(\%)$ & 0,195 & 0,195 & 0,195 & 0,242 & 0,242 & 0,242 & 0,160 & 0,160 & 0,160 \\
\hline
\end{tabular}

*Suplementos vitamínico e mineral fornecidos pela Poli Nutri Alimentos Ltda. Premix Vitamínico: Vitamina A- 1.875 .000 UI; Vitamina D3- 625.000 UI; Vitamina E- 3.750 mg; Vitamina K3- 300 mg; Tiamina- 375 mg; Riboflavina- 1.375 mg; Piridoxina- $500 \mathrm{mg}$; Vitamina B12- $3125 \mathrm{mg}$; Niacina- $8750 \mathrm{mg}$; Pantotenato de Cálcio- $2500 \mathrm{mg}$; Ácido Fólico- $150 \mathrm{mg}$; Biotina- $15 \mathrm{mg}$; Cloreto de Colina- $87.500 \mathrm{mg}$; Promotor de Crescimento- 10.000 mg; Coccidiostático- 25.000 mg; Antioxidante- $5.000 \mathrm{mg}$. Premix Mineral: Ferro- $50.000 \mathrm{mg}$; Cobre- $70.000 \mathrm{mg}$; Manganês- 60.000; Zinco- 50.000 mg; Iodo- $1.250 \mathrm{mg}$; Selênio- $200 \mathrm{mg}$.

Ciênc. agrotec., Lavras, v. 29, n. 6, p. 1248-1257, nov./dez., 2005 
O ganho de peso foi calculado no final de cada fase, sendo todos os frangos pesados aos 21, 35 e 42 dias de idade. $\mathrm{O}$ consumo de ração foi calculado para cada fase descontando-se a sobra da quantidade fornecida. A conversão alimentar foi calculada para cada fase por meio da divisão do consumo de ração pelo ganho de peso. A análise estatística dos resultados foi realizada de acordo com procedimento GLM (General Linear Models) do SAS (SAS INSTITUTE, 1991).

\section{RESULTADOS E DISCUSSÃO}

Os resultados encontrados para o ganho de peso, consumo de ração, conversão alimentar e mortalidade são apresentados nas Tabelas 2, 3, 4 e 5. Não houve efeito significativo dos níveis de substituição do milho pelo sorgo em nenhum dos parâmetros de desempenho estudados. Resultados semelhantes foram encontrados por Fernandes et al. (2002) que, ao compararem o desempenho produtivo de frangos de corte alimentados com dietas com milho, milho: sorgo e sorgo, não observaram diferenças significativas para os parâmetros de desempenho.

Os resultados encontrados para o rendimento de carcaça e das partes são apresentados na Tabela 6 .
Houve efeito significativo $(\mathrm{p}<0,05)$ do sexo para o rendimento de carcaça, sendo que os machos apresentaram maiores valores que as fêmeas nas dietas com milho e sorgo com baixo tanino. Os machos apresentaram maior rendimento de pernas e carne de pernas que as fêmeas $(\mathrm{p}<0,05)$ enquanto que as fêmeas apresentaram maior porcentagem de gordura abdominal e carne de peito que os machos $(\mathrm{p}<0,05)$. Resultados semelhantes foram encontrados por Gualtieri \& Rapaccini (1990).

Com relação à substituição do milho pelo sorgo não houve efeito significativo $(p>0,05)$ para o rendimento de nenhuma das partes. Resultados semelhantes foram encontrados por Gualtieri \& Rapaccini (1990) que, ao avaliarem três níveis de substituição do milho pelo sorgo (0, 50 e 100\%) em dietas de frangos de corte, não encontraram diferenças significativas para o peso vivo, rendimento da carcaça e rendimento dos cortes.

Para a conversão de kg de ração em kg de carne de peito e de pernas (Tabela 7), houve efeito significativo $(\mathrm{p}<0,05)$ do sexo, sendo que as fêmeas apresentaram os maiores resultados logo, os piores valores de conversão.

TABELA 2 - Ganho de peso (g) de frangos de corte alimentados com rações com milho, sorgo com alto tanino (SAT) e sorgo com baixo tanino (SBT).

\begin{tabular}{|c|c|c|c|c|c|}
\hline \multirow{2}{*}{$\begin{array}{l}\text { Idade } \\
\text { (Dias) }\end{array}$} & \multirow[b]{2}{*}{ Sexo } & \multicolumn{4}{|c|}{ Dietas } \\
\hline & & Milho & SAT & SBT & Média \\
\hline & Macho & 864 & 884 & 876 & 875 \\
\hline 1 a 21 & Fêmea & 845 & 859 & 847 & 850 \\
\hline $3,378^{*}$ & Média & 855 & 872 & 861 & - \\
\hline & Macho & 1318 & 1334 & 1296 & 1316 \\
\hline 22 a 35 & Fêmea & 1217 & 1289 & 1285 & 1264 \\
\hline $4,833^{*}$ & Média & 1267 & 1312 & 1290 & - \\
\hline & Macho & 649 & 680 & 652 & 660 \\
\hline 36 a 42 & Fêmea & 635 & 607 & 622 & 621 \\
\hline $4,286^{*}$ & Média & 642 & 643 & 637 & - \\
\hline & Macho & 2532 & 2501 & 2507 & 2513 \\
\hline 1 a 42 & Fêmea & 2548 & 2464 & 2501 & 2505 \\
\hline $3,339 *$ & Média & 2540 & 2483 & 2504 & - \\
\hline
\end{tabular}

*Coeficiente de Variação. Médias seguidas pela mesma letra maiúscula na coluna e mesma letra minúscula na linha não diferem significativamente pelo Teste de Tukey $(\mathrm{p}>0,05)$. 
TABELA 3 - Consumo de ração (g) de frangos de corte alimentados com rações com milho, sorgo com alto tanino (SAT) e sorgo com baixo tanino (SBT).

\begin{tabular}{|c|c|c|c|c|c|}
\hline \multirow{2}{*}{$\begin{array}{l}\text { Idade } \\
\text { (Dias) }\end{array}$} & \multirow[b]{2}{*}{ Sexo } & \multicolumn{4}{|c|}{ Dietas } \\
\hline & & Milho & SAT & SBT & Média \\
\hline & Macho & 1356 & 1403 & 1327 & $1362 \mathrm{~A}$ \\
\hline 1 a 21 & Fêmea & 1251 & 1348 & 1236 & $1279 \mathrm{~B}$ \\
\hline \multirow[t]{2}{*}{$2,468 *$} & Média & 1303 & 1375 & 1282 & - \\
\hline & Macho & 2149 & 2214 & 2226 & $2196 \mathrm{~A}$ \\
\hline 22 a 35 & Fêmea & 2058 & 2060 & 2108 & 2075 B \\
\hline \multirow[t]{2}{*}{$3,540 *$} & Média & 2103 & 2137 & 2167 & - \\
\hline & Macho & 1373 & 1278 & 1337 & 1329 \\
\hline 36 a 42 & Fêmea & 1319 & 1408 & 1311 & 1346 \\
\hline \multirow[t]{2}{*}{$3,489 *$} & Média & 1346 & 1343 & 1324 & - \\
\hline & Macho & 4878 & 4895 & 4891 & $4888 \mathrm{~A}$ \\
\hline 1 a 42 & Fêmea & 4629 & 4817 & 4656 & $4701 \mathrm{~B}$ \\
\hline $2,557 *$ & Média & 4753 & 4856 & 4774 & - \\
\hline
\end{tabular}

*Coeficiente de Variação. Médias seguidas pela mesma letra maiúscula na coluna e mesma letra minúscula na linha não diferem significativamente pelo Teste de Tukey $(\mathrm{p}>0,05)$.

TABELA 4 - Conversão Alimentar de frangos de corte alimentados com rações com milho, sorgo com alto tanino (SAT) e sorgo com baixo tanino (SBT).

\begin{tabular}{|c|c|c|c|c|c|}
\hline \multirow{2}{*}{$\begin{array}{l}\text { Idade } \\
\text { (Dias) }\end{array}$} & \multirow[b]{2}{*}{ Sexo } & \multicolumn{4}{|c|}{ Dietas } \\
\hline & & Milho & SAT & SBT & Média \\
\hline & Macho & 1,57 & 1,58 & 1,51 & 1,55 \\
\hline 1 a 21 & Fêmea & 1,48 & 1,57 & 1,46 & 1,50 \\
\hline $4,454^{*}$ & Média & $1,52 \mathrm{ab}$ & $1,58 \mathrm{a}$ & $1,48 \mathrm{~b}$ & - \\
\hline & Macho & 1,63 & 1,65 & 1,72 & 1,67 \\
\hline 22 a 35 & Fêmea & 1,69 & 1,60 & 1,64 & 1,64 \\
\hline $4,690^{*}$ & Média & 1,66 & 1,62 & 1,68 & - \\
\hline & Macho & 2,11 & 2,10 & 2,05 & 2,08 \\
\hline 36 a 42 & Fêmea & 2,07 & 2,07 & 2,10 & 2,08 \\
\hline $2,416^{*}$ & Média & 2,09 & 2,08 & 2,08 & - \\
\hline & Macho & 1,92 & 1,95 & 1,95 & $1,94 \mathrm{~A}$ \\
\hline 1 a 42 & Fêmea & 1,81 & 1,95 & 1,86 & $1,87 \mathrm{~B}$ \\
\hline $4,047^{*}$ & Média & 1,87 & 1,95 & 1,90 & - \\
\hline
\end{tabular}

*Coeficiente de Variação. Médias seguidas pela mesma letra maiúscula na coluna e mesma letra minúscula na linha não diferem significativamente pelo Teste de Tukey $(p>0,05)$. 
TABELA 5 - Mortalidade (\%) de frangos de corte alimentados com rações com milho, sorgo com alto tanino (SAT) e sorgo com baixo tanino (SBT).

\begin{tabular}{|c|c|c|c|c|c|}
\hline \multirow{2}{*}{$\begin{array}{l}\text { Idade } \\
\text { (Dias) }\end{array}$} & \multirow[b]{2}{*}{ Sexo } & \multicolumn{4}{|c|}{ Dietas } \\
\hline & & Milho & SAT & SBT & Média \\
\hline & Macho & 1,50 & 2,50 & 1,00 & 1,66 \\
\hline 1 a 21 & Fêmea & 1,50 & 0,00 & 2,50 & 1,33 \\
\hline $117,58^{*}$ & Média & 1,50 & 1,25 & 1,75 & - \\
\hline & Macho & 1,50 & 0,50 & 0,50 & 0,83 \\
\hline 22 a 35 & Fêmea & 0,00 & 0,00 & 0,00 & 0,00 \\
\hline $233,23^{*}$ & Média & 0,75 & 0,25 & 0,25 & - \\
\hline & Macho & 0,50 & 0,00 & 1,50 & 0,66 \\
\hline 36 a 42 & Fêmea & 0,50 & 0,00 & 0,00 & 0,16 \\
\hline $233,23^{*}$ & Média & 0,50 & 0,00 & 0,75 & - \\
\hline & Macho & 3,41 & 1,15 & 2,00 & 2,19 \\
\hline 1 a 42 & Fêmea & 1,63 & 0,00 & 3,00 & 1,54 \\
\hline $93,67^{*}$ & Média & 2,52 & 0,575 & 2,50 & - \\
\hline
\end{tabular}

*Coeficiente de Variação. Médias seguidas pela mesma letra maiúscula na coluna e mesma letra minúscula na linha não diferem significativamente pelo Teste de Tukey $(\mathrm{p}>0,05)$.

TABELA 6 - Rendimento de carcaça (\%) e das partes da carcaça (\%) de frangos de corte alimentados com ração com milho, sorgo com alto tanino (SAT) e sorgo com baixo tanino (SBT).

\begin{tabular}{|c|c|c|c|c|c|}
\hline \multirow[b]{2}{*}{ Parâmetro } & \multirow[b]{2}{*}{ Sexo } & \multicolumn{4}{|c|}{ Dietas } \\
\hline & & Milho & SAT & SBT & Média \\
\hline \multirow{3}{*}{$\begin{array}{l}\text { Rendimento de Carcaça } \\
1,87^{*}\end{array}$} & Macho & $72,09 \mathrm{Aa}$ & $71,31 \mathrm{~b}$ & $72,54 \mathrm{Aa}$ & 71,98 \\
\hline & Fêmea & $71,38 \mathrm{Ba}$ & $71,094 \mathrm{~b}$ & $71,00 \mathrm{Bb}$ & 71,14 \\
\hline & Média & 71,73 & 71,20 & 71,77 & - \\
\hline \multirow{3}{*}{$\begin{array}{c}\text { Rendimento de Pernas } \\
4,32^{*}\end{array}$} & Macho & 29,65 & 29,63 & 30,03 & $29,77 \mathrm{~A}$ \\
\hline & Fêmea & 29,16 & 28,61 & 28,70 & $28,82 \mathrm{~B}$ \\
\hline & Média & 29,41 & 29,12 & 29,36 & - \\
\hline \multirow{3}{*}{$\begin{array}{l}\text { Rendimento de Asas } \\
5,04^{*}\end{array}$} & Macho & 11,03 & 11,24 & 11,18 & 11,15 \\
\hline & Fêmea & 11,31 & 11,39 & 11,07 & 11,26 \\
\hline & Média & 11,17 & 11,31 & 11,12 & - \\
\hline \multirow{3}{*}{$\begin{array}{c}\text { Rendimento de Peito } \\
4,41^{*}\end{array}$} & Macho & 36,11 & 36,54 & 35,47 & 36,04 \\
\hline & Fêmea & 36,51 & 36,70 & 36,62 & 36,61 \\
\hline & Média & 36,31 & 36,62 & 36,05 & - \\
\hline \multirow{3}{*}{$\begin{array}{c}\text { Rendimento de Dorso } \\
6,10^{*}\end{array}$} & Macho & 22,99 & 21,86 & 23,12 & 22,66 \\
\hline & Fêmea & 22,55 & 23,04 & 23,19 & 22,93 \\
\hline & Média & 22,77 & 22,45 & 23,16 & - \\
\hline \multirow{3}{*}{$\begin{array}{c}\text { Gordura Abdominal } \\
22,50^{*}\end{array}$} & Macho & 2,18 & 2,29 & 2,36 & $2,28 \mathrm{~B}$ \\
\hline & Fêmea & 3,26 & 3,62 & 2,99 & $3,29 \mathrm{~A}$ \\
\hline & Média & 2,72 & 2,95 & 2,68 & - \\
\hline \multirow{3}{*}{$\begin{array}{c}\text { Rendimento de carne de Peito } \\
(\%) \\
6,29^{*}\end{array}$} & Macho & 26,26 & 25,91 & 25,95 & $26,04 \mathrm{~B}$ \\
\hline & Fêmea & 26,83 & 27,10 & 26,61 & $26,85 \mathrm{~A}$ \\
\hline & Média & 26,54 & 26,50 & 26,28 & - \\
\hline \multirow{3}{*}{$\begin{array}{c}\text { Rendimento de Carne de } \\
\text { Pernas }(\%) \\
5,09^{*} \\
\end{array}$} & Macho & 19,91 & 19,73 & 20,05 & $19,90 \mathrm{~A}$ \\
\hline & Fêmea & 19,58 & 19,07 & 19,16 & 19,27 B \\
\hline & Média & 19,75 & 19,40 & 19,61 & - \\
\hline
\end{tabular}

*Coeficiente de Variação. Médias seguidas pela mesma letra maiúscula na coluna e mesma letra minúscula na linha não diferem significativamente pelo Teste de Tukey $(\mathrm{p}>0,05)$. 
Os resultados encontrados para comprimento dos intestinos aos 14,21, 28, 35 e 42 dias de idade são apresentados na Tabela 8. Não houve efeito significativo ( $>>0,05)$ da substituição do milho pelo sorgo com alto tanino ou baixo tanino sobre o comprimento do duodeno, jejuno, íleo, ceco e comprimento total em nenhuma das idades avaliadas. Resultados diferentes foram observados por Nunes et al. (2001) e Ortiz et al. (1994), que ao realizarem um estudo com aves em crescimento consumindo dietas contendo $0 ; 8$ e $16 \mathrm{~g} / \mathrm{kg}$ de tanino, observaram mudanças morfológicas significativas na mucosa intestinal das aves.

TABELA 7 - Conversão de ração em carne de peito e pernas $(\mathrm{kg} / \mathrm{kg})$ de frangos de corte alimentados com ração com milho, com sorgo alto tanino (SAT) e sorgo com baixo tanino (SBT).

\begin{tabular}{cccccc}
\hline & & \multicolumn{3}{c}{ Dietas } \\
\cline { 3 - 6 } Parâmetro & Sexo & Milho & SAT & SBT & Média \\
\hline Conversão de Ração em & Macho & 8,58 & 9,72 & 9,14 & 9,15 B \\
Carne de Peito & Fêmea & 11,08 & 11,58 & 10,44 & 11,04 A \\
$12,62^{*}$ & Média & 9,83 & 10,65 & 9,81 & - \\
\hline Conversão de Ração em & Macho & 11,91 & 12,84 & 12,91 & 12,55 B \\
Carne de Pernas & Fêmea & 14,71 & 14,73 & 14,32 & 14,59 A \\
$6,82^{*}$ & Média & 13,31 & 13,79 & 13,62 & - \\
\hline
\end{tabular}

*Coeficiente de Variação. Médias seguidas pela mesma letra maiúscula na coluna e mesma letra minúscula na linha não diferem significativamente pelo Teste de Tukey ( $p>0,05)$.

TABELA 8 - Comprimento do duodeno, jejuno, íleo ceco e total (cm) de frangos de corte aos 14, 21, 28, 35 e 42 dias de idade, alimentados com ração com milho, sorgo com alto tanino (SAT) e sorgo com baixo tanino (SBT).

\begin{tabular}{|c|c|c|c|c|c|}
\hline \multirow{2}{*}{\multicolumn{2}{|c|}{ Região }} & \multirow{2}{*}{$\begin{array}{l}\text { Idade } \\
\text { (dias) }\end{array}$} & \multicolumn{3}{|c|}{ Dietas } \\
\hline & & & Milho & SAT & SBT \\
\hline Duodeno & $11,22 *$ & & 19,041 & 18,416 & 18,916 \\
\hline Jejuno & $11,02 *$ & & 45,917 & 46,875 & 44,958 \\
\hline Íleo & $10,99 *$ & & 42,708 & 45,000 & 44,500 \\
\hline Ceco & $9,20 *$ & 14 & 25,750 & 25,583 & 24,791 \\
\hline Total & $8,05^{*}$ & & 133,417 & 135,875 & 131,167 \\
\hline Duodeno & $8,76^{*}$ & & 25,250 & 24,083 & 23,791 \\
\hline Jejuno & $11,01^{*}$ & & 54,750 & 52,292 & 52,667 \\
\hline Íleo & $11,32 *$ & & 52,208 & 50,625 & 51,792 \\
\hline Сeco & $7,63^{*}$ & 21 & 31,750 & 33,000 & 33,291 \\
\hline Total & $7,63^{*}$ & & 163,958 & 160,000 & 161,542 \\
\hline Duodeno & $9,21^{*}$ & & 26,958 & 27,041 & 26,958 \\
\hline Jejuno & $10,29 *$ & & 58,417 & 57,708 & 56,833 \\
\hline Íleo & $9,14^{*}$ & & 58,958 & 57,083 & 57,625 \\
\hline Ceco & $7,27 *$ & 28 & 39,625 & 39,291 & 39,166 \\
\hline Total & $6,46^{*}$ & & 183,458 & 181,125 & 180,583 \\
\hline Duodeno & $9,54 *$ & & 28,791 & 28,041 & 29,250 \\
\hline Jejuno & $12,64 *$ & & 60,542 & 61,500 & 62,500 \\
\hline Íleo & $10,80 *$ & & 65,250 & 64,542 & 64,042 \\
\hline Сeco & $6,31 *$ & 35 & 45,250 & 45,500 & 46,208 \\
\hline Total & $7,42 *$ & & 199,833 & 199,583 & 202,000 \\
\hline Duodeno & $7,88^{*}$ & & 31,083 & 29,875 & 29,916 \\
\hline Jejuno & $10,44 *$ & & 67,125 & 66,250 & 67,125 \\
\hline Íleo & $9,70 *$ & & 69,542 & 67,375 & 71,292 \\
\hline Ceco & $8,65^{*}$ & 42 & 46,208 & 46,583 & 47,292 \\
\hline Total & $7,01^{*}$ & . & 213,958 & 210,083 & 215,625 \\
\hline
\end{tabular}

Ciênc. agrotec., Lavras, v. 29, n. 6, p. 1248-1257, nov./dez., 2005 
Os resultados encontrados para a porcentagem das vísceras e intestinos aos 14, 21, 28, 35 e 42 dias de idade são apresentados na Tabela 9. Não houve efeito significativo $(p>0,05)$ da substituição do milho pelo sorgo de alto tanino ou baixo tanino sobre a porcentagem das vísceras em nenhuma das idades avaliadas. Estes resultados diferem daquilo que foi afirmado por Ahmed et al. (1991), Brown et al. (1985) e Nyvachot \& Atkinson (1995), para os quais, o peso dos órgãos é geralmente avaliado na observação da resposta do organismo animal a certos tratamentos, já que esses órgãos podem apresentar uma hipo ou hipertrofia dependendo das condições nutricionais as quais são submetidos, como é o caso da presença de tanino na dieta. Nunes et al. (2001) observaram que ao substituir o milho pelo sorgo em dietas de frangos de corte, houve uma atrofia na mucosa do íleo e encurtamento das vilosidades, resultando em uma distorção de sua arquitetura, edema no tecido conectivo das vilosidades, hiperplasia e hipertrofia das células de goblet (secreção de muco), além de hipertrofia da glândula parótida. Resultados semelhantes já haviam sido observados por Magalhães et al. (1997).

TABELA 9 - Porcentagem do pró-ventrículo, moela, pâncreas, fígado e intestinos de frangos de corte aos 14, 21, 28, 35 e 42 dias de idade, alimentados com ração com milho, sorgo com alto tanino (SAT) e sorgo com baixo tanino (SBT).

\begin{tabular}{|c|c|c|c|c|c|}
\hline \multirow{2}{*}{\multicolumn{2}{|c|}{ Vísceras }} & \multirow{3}{*}{$\begin{array}{l}\text { Idade } \\
\text { (dias) }\end{array}$} & \multicolumn{3}{|c|}{ Dietas } \\
\hline & & & Milho & SAT & SBT \\
\hline Pró-ventrículo & $9,12 *$ & & 0,740 & 0,787 & 0,753 \\
\hline Moela & $4,60 *$ & & 3,027 & 3,080 & 2,991 \\
\hline Pâncreas & $2,96^{*}$ & & 0,438 & 0,433 & 0,387 \\
\hline Fígado & $8,61 *$ & 14 & 2,880 & 2,920 & 2,889 \\
\hline Intestinos & $9,06^{*}$ & & 5,633 & 5,972 & 5,844 \\
\hline Pró-ventrículo & $5,11^{*}$ & & 0,537 & 0,584 & 0,586 \\
\hline Moela & $11,14^{*}$ & & 2,315 & 2,436 & 2,333 \\
\hline Pâncreas & $7,57 *$ & 21 & 0,353 & 0,336 & 0,331 \\
\hline Fígado & $8,16^{*}$ & & 2,611 & 2,698 & 2,623 \\
\hline Intestinos & $11,15^{*}$ & & 4,497 & 4,824 & 4,941 \\
\hline Pró-ventrículo & $7,23^{*}$ & & 0,481 & 0,521 & 0,496 \\
\hline Moela & $11,62^{*}$ & & 1,928 & 1,935 & 1,789 \\
\hline Pâncreas & $7,51 *$ & 28 & 0,321 & 0,291 & 0,298 \\
\hline Fígado & $10,28^{*}$ & & 2,445 & 2,311 & 2,313 \\
\hline Intestinos & $10,79 *$ & & 4,390 & 4,456 & 4,437 \\
\hline Pró-ventrículo & $8,49 *$ & & 0,391 & 0,417 & 0,415 \\
\hline Moela & $11,87^{*}$ & & 1,573 & 1,581 & 1,377 \\
\hline Pâncreas & $4,19 *$ & 35 & 0,219 & 0,214 & 0,207 \\
\hline Fígado & $10,67 *$ & & 1,857 & 1,862 & 1,863 \\
\hline Intestinos & $10,69 *$ & & 3,674 & 3,789 & 3,987 \\
\hline Pró-ventrículo & $7,47 *$ & & 0,382 & 0,418 & 0,386 \\
\hline Moela & $12,03^{*}$ & & 1,437 & 1,484 & 1,403 \\
\hline Pâncreas & $2,26^{*}$ & 42 & 0,234 & 0,226 & 0,228 \\
\hline Fígado & $8,94 *$ & & 1,921 & 1,898 & 1,905 \\
\hline Intestinos & $10,42 *$ & & 3,830 & 3,806 & 3,960 \\
\hline
\end{tabular}

*Coeficiente de Variação. Médias seguidas pela mesma letra maiúscula na coluna e mesma letra minúscula na linha não diferem significativamente pelo Teste de Tukey $(p>0,05)$. 


\section{CONCLUSÃO}

Com base nos resultados pode-se concluir que, ao utilizar sorgo com alto tanino $(1,89 \mathrm{~g} / \mathrm{kg})$ e sorgo com baixo tanino $(0,49 \mathrm{~g} / \mathrm{kg})$ em substituição ao milho nas rações de frangos de corte não ocorre alterações dos parâmetros de desempenho, rendimento de carcaça, porcentagem das vísceras e intestinos e medidas dos intestinos que possam comprometer tal substituição.

\section{AGRADECIMENTOS}

Fundação de Amparo á Pesquisa do Estado de São Paulo (FAPESP), Monsanto S.A. e Multimix Nutrição Animal.

\section{REFERÊNCIAS BIBLIOGRÁFICAS}

AHMED et al. Activities of enzymes, of the pâncreas and the lúmen and mucosa of the small intestine in growing broiler cockerels fed on tannin-containing diets. British Journal of Nutrition, Cambridge, n. 65, p. 189-197, 1991.

BROWN, D. R.; SOUTHERN, L. L.; BAKER, D. H. A comparison of methods for organ weight data adjustments in chicks. Poultry Science, Champaign, n. 64, p. 366-369, 1985.

DOUGLAS, J. H. et al. Nutrient composition and metabolizable energy values of selected sorghum varieties and yelow corn. Poultry Science, Champaign, n. 69, p. 1147-1155, 1990.

ELKIN, R. G. et al. Condensed tannins are only partially responsible for variations in nutrient digestibilities of sorghum grain cultivars. Poultry Science, Champaigh, n. 74, p. 125, 1995. Supplement 1. Abstract.

FERNANDES, E. A.; MARCACINE, B. A.; TESINI, J. R. M. Substituição do milho por sorgo com e sem adição de enzimas em rações para frangos de corte. In: CONFERÊNCIA APINCO DE CIÊNCIAETECNOLOGIAAVÍCOLAS, 2002, Campinas, SP. Anais... Campinas: FACTA, 2002. p. 34.

GUALTIERI, M.; RAPACCINI, S. Sorghum grain in poultry feeding. World's Poultry Science Journal, Ithaca, n. 46, p. 246-254, 1990.

HASLAM, E. Vegetable tannins. In: COHN, E. E. (Ed.). The biochemistry of plants. New York: Academic, 1981. p. 527-544.

IBRAHIM, S.; MOHAMMED, K. S.; SOLIMAN, H.; ANWAR, A. Recommended levels of available phosphorus for broilers fed starting diets containing Sudanese sorghum. Nutrition Abstract Reviews, Farnham, v. 61, p. $61,1991$.

LESSON, S.; SUMMERS, J. D. Commercial poultry nutrition. Ontário: University Books, 1991.

MAGALHÃES, P. C.; RODRIGUES, W. A.; DURÃES, F. O. M. Tanino no grão de sorgo: bases fisiológicas e métodos de determinação. Sete Lagoas: EMBRAPA-CNPMS, 1997.

MARTINS et al. Silagem de grãos úmidos de milho na alimentação de frangos de corte: peso dos órgãos e morfometria intestinal. In: CONFERÊNCIA APINCO DE CIÊNCIA E TECNOLOGIAAVIICOLA, 2000, Campinas. Anais... Campinas: FACTA, 2000. p. 49.

MENDES, A. A. Efeito de fatores genéticos, nutricionais e de ambiente sobre $o$ rendimento de carcaça de frangos de corte. 1990. 103 f. Tese (Livre Docência) - Universidade do Estado de São Paulo, Botucatu, 1990.

MITJAVILA, S. et al. Tannic acid and oxidised tannic acid on the functional state of rat intestinal epithelium. Journal of Nutrition, Philadelphia, v. 107, p. 2113-2121, 1977.

MORAN, E. T. Comparative nutrition of fowl and swine: the gastrointestinal systems. Guelph: University of Guelph, 1982.

MUSHARAF, N. A.; LATSHAW, J. D. Effect of tannin extraction on the feeding value of grain sorghum in broiler starter diets. Sudan Journal of Animal Production, [S.1.], v. 4, n. 53, p. 64, 1991.

NUNES, R. V. et al. Fatores antinutricionais dos ingredientes destinados à alimentação animal. In: SIMPÓSIO SOBRE INGREDIENTES NAALIMENTAÇÃO ANIMAL, 2001, Campinas. Anais... Campinas: CBNA, 2001. p. 235-266.

NYVACHOTI, C. M.; ATKINSON, J. L. The effect of feeding high-tanning sorghum on digestive organ response and overall performance of broiler chicks. Poultry Science, Champaign, v. 74, p. 125, 1995. Supplement 1. Abstract.

ORTIZ, L. T. et al. Tannins in faba bean seeds: effects on the digestion of protein and amino acids in growing chicks. Animal Feed Science and Technology, Amsterdam, v. 41, p. 271-278, 1994. 
ROSTAGNO, H. S.; ALBINO, L. F. T.; DONZELE, J. L. SCOTT, M. L. et al. Nutrition of the chicken. Ithaca: M.L. Tabelas brasileiras para aves e suínos: composição Scott and Associates, 1982.

de alimentos e exigências nutricionais. Viçosa: UFV, 2000. $141 \mathrm{p}$.

TREVINO, J. et al. Effects of tannin from faba beans (Vicia faba) on the digestion of starch by growing chicks. Animal Feed SAS INSTITUTE. SAS user's guide. Cary, 1991. Science and Technology, Amsterdam, v. 37, p. 345-349, 1992. 